\title{
Implicit associative responses influence encoding in memory
}

\author{
DAVID J. BRYANT \\ Stanford University, Stanford, California
}

\begin{abstract}
In list-learning experiments, the orienting question asked of one item may influence the processing of, and memory for, later items in the list. Four experiments demonstrated that words that are not related to their own orienting question, but that are semantically related to the question asked of a previous item, are better recalled than are words that are not related to any question in the list. Factors that influence this memory enhancement include the number of times relevant orienting questions appear during study, as well as the retention interval. Experiment 4 revealed that this effect is contingent upon conscious awareness: Item-category relations do not enhance recall if the subject is not aware of them. The results of the four experiments imply that semantic categories can be primed as implicit associative responses to words, which influence memory.
\end{abstract}

Researchers of human memory have long been interested in how thoughts about an event are related to memory of that event. Early interest was focused on how various mental operations or orienting tasks that individuals carry out on verbal materials influence their subsequent memory for those materials (Lockhart, Craik, \& Jacoby, 1976). The levels of processing (LOP) framework (Craik \& Lockhart, 1972), for example, grew out of this tradition and sought to relate memory performance to the nature and kinds of mental activity that an individual engages in at the time of encoding. One finding made in the LOP tradition is that items studied according to semantic criteria are better remembered than are those judged according to nonsemantic criteria (Craik \& Tulving, 1975; Hyde \& Jenkins, 1969). Another finding is that words that fit the category of their orienting question (e.g., WHALE is a "yes" item for the question "Is it a mammal?") are recalled better than are words that do not fit the question (e.g., PENCIL is a "no" item for the same question; see Craik \& Tulving, 1975; Jacoby \& Craik, 1979). Given the importance of encoding operations for memory, most theories of memory, including associative models such as HAM (Anderson \& Bower, 1972, 1973) and SAM (Raaijmakers \& Shiffrin, 1980, 1981) and multiple trace models such as Hintzman's $(1984,1986)$ MINERVA, have been designed to account for the differential impact on memory of various semantic and nonsemantic encoding tasks. Some, such as Eich's (1982) distributed memory model, CHARM, have been directly applied to LOP phenomena (Eich, 1985).

\footnotetext{
This research was supported by National Institute of Mental Health Grant MH 13950 and AFOSR Grant 87-0282 to Gordon H. Bower. I am extremely grateful to Gordon Bower for his guidance, support, and invaluable advice. Thanks also go to Chris Kortge, Richard Marsh, Peter Todd, and Barbara Tversky for their assistance, and to Robert Greene, Robert Lockhart, and Douglas Nelson for their helpful reviews. Correspondence concerning this article may be addressed to David Bryant, Department of Psychology, Stanford University, Stanford, CA 94305.
}

An important limitation of the LOP framework and theories applied to orienting-task experiments is that they focus exclusively on the processing that occurs with respect to a given target word as it is presented and how this particular encoding context overlaps with the later retrieval context (Moscovitch \& Craik, 1976). The LOP framework, for example, describes the influence of a single orienting question on memory for a single item. A possibility that is usually neglected concerns the influence on memory for an item of orienting questions asked about other items in the list. In a list-learning experiment, the encoding of a word occurs within the organizational context of the study list as a whole. A reasonable question to pose is whether this whole-list context influences encoding and recall of a given item within the list. It may be that the orienting task employed in encoding one item will influence the encoding of another item. If so, it should be possible to greatly affect recall of a target word by varying the type of processing being carried out on other words in the study list.

The idea that the encoding of an item can be influenced by the other items a subject learns is not a new one, having historical precedent in early research on organization in free recall (e.g., Bousfield, 1953; Bousfield \& Cohen, 1958; Cofer, 1965). Indeed, Cofer (1965) foreshadows the research to be described here in his hypothesis that subjects in memory experiments actively seek categorical and associational relations between items in a list to aid in their organization of the material. Subjects undoubtedly generate associations while learning material. Studies by Underwood and associates (e.g., Ekstrand, Wallace, \& Underwood, 1966; Underwood, 1965; Underwood \& Schulz, 1960) demonstrate that subjects in a list-learning experiment are likely to think of associated words and superordinate categories, often mistakenly believing that these associated items had actually occurred as list items. Underwood (1965) termed these generated associations implicit associative responses (IARs). 
The question under investigation is what effect implicit associations have on encoding. Recent studies have found that the level of recall of words learned in a list is partially determined by the size of the item's associative set. either taxonomic or rhyming (Nelson, Bajo, \& Canas, 1987; Nelson \& McEvoy, 1979). Nelson (1989) concludes that presenting a word activates related concepts, which can themselves be encoded and influence memory for the presented material. From this analysis, one might ask what factors determine whether a related concept will be activated. The general hypothesis to be tested is that a word which elicits an associated superordinate category dur ing encoding will benefit from the encoding of that association, and that the probability of eliciting and encoding this association is enhanced by recent experience with the category.

The aim of the present study was to test this general idea by exploiting the fact that, in LOP experiments, words that are "yes" items to their orienting questions are recalled better than are words that are "no" items. Although this effect has several theoretical interpretations (see, e.g., Bower, 1975; Craik \& Tulving, 1975), it will be used here as an instrument for measuring the impact of related processing of other items on target-item recall. Specifically, the experiments reported here examined whether the typically poor recall of a "no" target item could be improved by having that item occur in a list in which it was related to an orienting question asked about another, earlier item. The general hypothesis was that the thoughts an individual has while encoding one target item can prime and make available that same category of thoughts when the individual encounters and encodes later target items in the input list. Thus, memory for target items will be influenced not only by the orienting task applied to them, but also by the orienting tasks applied to other items.

\section{EXPERIMENT 1}

Experiment 1 examined whether memory for a "no" item could be enhanced by its positive relation to an orienting question asked about other words in the list. Lists of to-be-remembered words were constructed such that each item was paired with a study question in either a positive ("yes") or a negative ("no") relation. Some of the negative-response items were related to a question asked about another word in the list; these were dubbed "yes/ no" items. The remaining "no" items were not related to any questions in the list; these were called "pure no" items. An effect of related question was sought for both semantic category questions (in taxonomically organized lists) and rhyming questions (in phonetically organized lists). In half of the study lists, the questions pertained to membership in semantic categories, such as "Is this an ANIMAL?"; in the remaining lists, the questions pertained to rhyming relations, such as "Does this word rhyme with BOAT?" It was expected that "yes/no" items, which were related to a question directed at another item, would be better recalled than would "pure no" items, but that this effect would be weaker in the rhyming-words lists than in the taxonomically organized lists because phonetic encoding tasks, in general, produce lower levels of recall (Craik \& Tulving, 1975: Moscovitch \& Craik. 1976).

\section{Method}

Subjects. Twenty-four Stanford undergraduates participated in Experiment $I$ in partial fulfillment of an introductory psychology course requirement.

Materials. Materials consisted of four lists of 48 to-beremembered words and 12 study questions (each paired with 4 tobe-remembered words). Two of the lists were taxonomically organized, and two were organized on the basis of rhyming relations.

The study questions in the taxonomically organized lists were composed of questions of category membership that had been phrased around 24 of Battig and Montague's (1969) categories (e.g., given the category WEAPON, "Is it a WEAPON?" ). Four words were paired with each of the 24 questions to form two lists of 48 question-word pairings. In each case, two words were members of the question category and two were not members of the category. Positively related words ("yes" items) were strong associates of their category ( mean frequency of generation by 442 subjects $=377.55: S D=$ 48.45 ) selected from the category associates published by Battig and Montague (1969). For 16 of the questions ( 8 in each list), negative responses were selected from the University of Toronto word pool and were unrelated to any category in the list ("no" items). For eight of the questions (four in each list), negative responses were selected from Battig and Montague (1969) and were unrelated to the study question they were paired with, but were strong associates (mean frequency $=315.75 ; S D=73.63$ ) of a category that occurred elsewhere in the list ("yes/no" items).

The structure of the study lists is diagrammed in Table 1 . Four of the category questions (unrelated questions) were set aside as a control set. This set replicates those used in the procedure involved in a standard LOP experiment. The "no" items of the four questions were unrelated to any question in the list. Furthermore, no words other than their own "yes" responses were related to these questions. Another set of four category questions (related questions) were set aside as the questions to which "yes/no" items were related. The "no" items to these four questions also were not related to any question in the list. The remaining four category questions (experimental questions) were paired with the "yes/no" items that were unrelated to their own orienting question but were related to one of the related category questions. The distinction between these three sets of questions turned out to be irrelevant in terms of their effect on recall performance. and no distinction will be made between them henceforth. The main condition for comparison of items was item type: "yes," "no," and "yes/no."

The structure of the two rhyming lists paralleled that of the taxonomic lists (see Table 1). The words that served as the 24 rhyme categories in the study questions were selected randomly from the University of Toronto word pool. Two lists of 48 words were composed, each containing four occurrences of 12 different rhyming questions. To-be-remembered words were selected from the Penguin Rhyming Dictionary (1985). ${ }^{1}$ The rhyming lists were made up of the same type of items ("yes," "no," and "yes/no").

The experiment was partially conducted on an Apple Ile computer. Questions and to-be-remembered materials were presented on the computer screen, and the subjects used the keyboard to answer the orienting questions during the study phases. After studying each list, the subject completed a free-recall test on a blank sheet of paper.

Design. The independent variables were the type of item ("yes," "yes/no," or "no") and the type of list (taxonomic or rhyming). 
Table 1

Examples of Taxonomic and Rhyming-Words List Structures Employed in Experiment 1

\begin{tabular}{|c|c|c|c|c|c|c|c|c|}
\hline \multirow[b]{2}{*}{$\begin{array}{c}\text { Category } \\
\text { Type }\end{array}$} & \multicolumn{4}{|c|}{ Taxonomic Lists } & \multicolumn{4}{|c|}{ Rhyming-Words Lists } \\
\hline & Example & $\begin{array}{c}\text { Response } \\
\text { Type }\end{array}$ & Example & $\begin{array}{c}\text { Related } \\
\text { to: }\end{array}$ & Example & $\begin{array}{c}\text { Response } \\
\text { Type }\end{array}$ & Example & $\begin{array}{c}\text { Rhymes } \\
\text { with: }\end{array}$ \\
\hline Unrelated & $\begin{array}{l}\text { A RELATIVE } \\
\text { A RELATIVE }\end{array}$ & $\begin{array}{l}\text { Yes } \\
\text { No }\end{array}$ & $\begin{array}{l}\text { Father } \\
\text { Echo }\end{array}$ & RELATIVE & $\begin{array}{l}\text { LANE } \\
\text { LANE }\end{array}$ & $\begin{array}{l}\text { Yes } \\
\text { No }\end{array}$ & $\begin{array}{l}\text { Pain } \\
\text { Salad }\end{array}$ & LANE \\
\hline Related & $\begin{array}{l}\text { A METAL } \\
\text { A METAL }\end{array}$ & $\begin{array}{l}\text { Yes } \\
\text { No }\end{array}$ & $\begin{array}{l}\text { Iron } \\
\text { Music }\end{array}$ & METAL & $\begin{array}{l}\text { FLOUR } \\
\text { FLOUR }\end{array}$ & $\begin{array}{l}\text { Yes } \\
\text { No }\end{array}$ & $\begin{array}{l}\text { Sour } \\
\text { Paint }\end{array}$ & FLOUR \\
\hline Experimental & $\begin{array}{l}\text { A COLOR } \\
\text { A COLOR }\end{array}$ & $\begin{array}{c}\text { Yes } \\
\text { Yes/No }\end{array}$ & $\begin{array}{l}\text { Blue } \\
\text { Steel }\end{array}$ & $\begin{array}{l}\text { COLOR } \\
\text { METAL }\end{array}$ & $\begin{array}{l}\text { GLOVE } \\
\text { GLOVE }\end{array}$ & $\begin{array}{c}\text { Yes } \\
\text { Yes/No }\end{array}$ & $\begin{array}{l}\text { Shove } \\
\text { Hour }\end{array}$ & $\begin{array}{l}\text { GLOVE } \\
\text { FLOUR }\end{array}$ \\
\hline
\end{tabular}

The dependent variable was the number of target words produced in free recall. Experiment 1 had a completely within-subject randomized design.

Each to-be-remembered item was paired with a study question, and all subjects studied a given item in the context of the same question. Items within a list were randomly ordered for each subject, with the provision that at least one instance of the related category of a "yes/no" item must occur before that item was allowed to appear. A set of three question-word pairings, selected from the same sources as critical items, preceded and followed the critical portion of each list as primacy and recency buffers. The subjects studied a total of four lists in the experiment; they studied each list and completed a free-recall and a cued-recall test for it before proceeding to the next list. Twenty-four list orders were possible, and order was counterbalanced across subjects by presenting lists in a unique order to each subject.

Procedure. The subjects were instructed that they were participating in an experiment concerning memory for common English words. The subjects studied a sequence of four lists of 54 words by responding to a question about each word. The question and word appeared together on a computer screen, and the subject indicated his/her answer to the question by pressing the $\mathrm{Y}$ key on the computer keyboard for "yes" or the N key for "no." Question-word pairs remained on the screen for approximately $2 \mathrm{sec}$, before being replaced by the next pair. The study questions in the taxonomic lists required the subjects to classify the target word (e.g., "Is it a WEAPON?"). The study questions in the rhyming lists concerned rhyming relations, such as "Does it rhyme with BOAT?"

Following the study phase of each list, the subject was given a free-recall test and asked to write down (in any order) as many of the target words from the preceding list as he/she could. The subject was requested to limit the recall to just those words that had appeared on the preceding list.

\section{Results and Discussion}

The results of the taxonomic and rhyming conditions are shown in Table 2 . The data from Lists 1 and 2 were pooled in the taxonomic condition; the data from Lists 3 and 4 were pooled in the rhyming condition. ${ }^{2}$

Both the type of list (taxonomic or rhyming) and the type of item ("yes," "yes/no," or "no") had a large impact on free recall. A two-factor analysis of variance revealed significant effects of type of list $[F(1,23)=$ $172.22, p<.0001]$, type of item $[F(2,46)=116.32$, $p<.0001]$, and their interaction $[F(2,46)=38.00$, $p<.0001]$. Thus, recall was greater overall in the taxonomic lists than in the rhyming-words lists, and recall of "yes" items exceeded that of "no" items in both the taxonomic $[t(23)=14.85, p<.0001]$ and the rhyming conditions $[t(23)=4.91, p<.0001] .{ }^{3}$ These main effects replicate the standard LOP findings of superior recall given semantic encoding operations and positive relations between stimulus items and orienting questions (see, e.g., Craik \& Tulving, 1975). The major finding, however, was that recall of "yes/no"' items was significantly greater than recall of "no" items in the taxonomic condition $[t(23)=7.96, p<.001]$, but not in the rhyming condition $[t(23)=0.36, p>.70]$. Recall of negative-response items was enhanced only when a related taxonomic category appeared elsewhere in the study list.

Conclusions. The main finding of the taxonomic condition was that when a negative-response item was related to a question appearing elsewhere in the study list, it was more likely to be remembered than if it had not been related to such question-what could be called a yes/no effect. This improvement in recall, however, was not equal in magnitude to the enhancement conveyed by being related to the question directed at the item at the time of study. In Experiment 1, an item that was a "yes" response to a question was most likely to be recalled. "Yes" items in the phonetic condition elicited superior recall, whereas recall of "yes/no" items was no better than that of "no" items. With respect to the original question of Experiment 1, recall of words in a list can be enhanced by a positive relation to a study question, but only if the question is a category question (as opposed to a rhyming question). These findings imply that, to encode a given word, subjects are able to use, explicitly or implicitly, the semantic, but not necessarily the phonetic, categories throughout a list.

The results of Experiment 1 can be understood in terms of implicit mental contiguity (Jacoby, 1974). Mental contiguity refers to the bringing together, in mental experience, of two physically disparate items such that these items can interact during encoding. If we assume that subjects generate superordinate categories when studying words in a list-learning experiment (Nelson et al., 1987; Underwood, 1965) and that encoding the relation between category and word enhances memory (Craik \& Tulving,

Table 2

Proportion Free Recalled in Taxonomic and Rhyming-Words Lists (Experiment 1)

\begin{tabular}{lccc}
\hline & \multicolumn{3}{c}{ Item Type } \\
\cline { 2 - 4 } \multicolumn{1}{c}{ List Type } & Yes & Yes/No & No \\
\hline Taxonomic & 0.52 & 0.29 & 0.08 \\
Rhyming-Words & 0.20 & 0.08 & 0.09 \\
\hline
\end{tabular}


1975), then Experiment 1 demonstrates that recent experience with a category increases the probability that the category will be elicited as an IAR by a related item and used to encode it. In other words, if subjects were able to recollect an appropriate category when confronted with a "yes/no" item, they were able to rehearse its relation to the "yes/no" item, enhancing its memorability.

Rhyming relations have been found to influence both recall (Nelson \& McEvoy, 1979) and priming (Lupker \& Williams, 1989). Thus, it is somewhat surprising that a yes/no effect was not found in the rhyming-words lists of Experiment 1. The subjects attended to the rhyme dimension while encoding items in the rhymingwords lists, a necessary condition for producing rhymeassociative set effects (Nelson et al., 1987). Yet, there is no evidence that recent experience with a rhyming word increased the likelihood of the subject's generating that word as an IAR during encoding. It appears that the yes/no effect occurs only in taxonomically organized lists.

There is a problem with Experiment 1, however, in that, in addition to being related to a previous category question, "yes/no" items were related to the "yes" items that had been paired with that category. Thus, "yes" and "yes/no" items existed in categorized sets within the study lists. The "no" items, on the other hand, were not similarly categorized, having been selected randomly. There is a possibility that the superior recall of "yes/no" items, relative to "no" items, may simply reflect the superior recall of categorized, as opposed to noncategorized, words (Marshall, 1967; Wood \& Underwood, 1967). Experiment 2 addressed this concern, while examining several factors that influence the yes/no effect.

\section{EXPERIMENT 2}

The purpose of Experiment 2 was twofold. First, it was intended to determine whether the yes/no effect was due to the relation of "yes/no" items to category questions presented during study or due to their being part of an interassociated set of words in the study list. To control for the foregoing differences between "no" and "yes/no" items, groups of "pure no" items were selected from categories in the Battig and Montague (1969) norms. In one condition, "no" items consisted of 12 words selected from three categories that were not used as study questions. This was intended to ensure that any subsequent difference in recall would be attributable to the critical manipulation of having "yes/no" items related to a category question that appeared in the list, rather than being attributable to differences in the number of related words appearing in the study list.

The second purpose of Experiment 2 was to examine what impact several factors would have on the yes/no effect. It has been assumed that if a taxonomic category is presented in the guise of a study question, then the category is primed to be elicited as an IAR to related words that appear later in the list. In an attempt to increase that priming in Experiment 1, each category was presented four times. One factor that should influence the size of the yes/no effect is the number of times a subject experiences each category in the list. If subjects use particular category questions fewer times, those categories should be less primed as IARs, translating into poorer recall of "yes/no" items, because subjects would be less likely to think of, and use, the relevant category at the time of encoding. To explore this issue, half of the subjects in Experiment 2 were presented a list comprised of 12 categories paired with four words each, and the other subjects were presented a list comprised of 24 categories paired with two words each. It was expected that the yes/no effect in free recall would be reduced in the case of 24 categories presented only twice each.

Another factor that might influence the size of the yes/no effect is the strength of semantic association between "yes/no" items and their related categories. If the "yes/no" items in the taxonomic lists benefit from the strengthening of a preexisting association to their related categories, a weaker association should be less effective in aiding subsequent recall than should a stronger one. The likelihood that a "yes/no" item will evoke the category question at the time of encoding should increase with its associative strength. Experiment 2 was also designed to determine what impact a delay between study and testing would have on recall performance, specifically the difference between "yes/no" and "no" items. If the benefit to recall of "yes/no" items results from a transitory strengthening of preexisting category relations, then this benefit should dissipate over time, and the yes/no effect should disappear.

Experiment 2 employed the same basic design as Experiment 1 , except for the following changes. The "no" items in the study list were selected from categorized sets, but their categories never appeared as study questions. The subjects studied a list of items that consisted of either 12 categories paired with four words each or 24 categories paired with two items each, and they recalled the studied list either immediately or after a 15-min delay. In addition, half of the words in the list were strong associates and half were weak associates of the category they belonged to.

\section{Method}

Subjects. Forty-eight Stanford undergraduates participated in Experiment 2 in exchange for either credit in an introductory psychology class or pay. The subjects were run in groups of 1 to 3 and served in Experiments 2 and 3 at the same time.

Materials. Two versions of a single study list were employed: one was made up of 12 categories paired with four words each (the four-item/category condition), the other was made up of 24 categories paired with two words each (the two-item/category condition). In addition, the categories and words were counterbalanced between conditions so that each of the 24 categories in the twoitem/category condition was used an equal number of times in the four-item/category condition. Likewise, each of the four words paired with each category in the four-item/category condition was used an equal number of times in the two-item/category condition. The structure of these lists differed somewhat from the taxonomic lists of Experiment 1. Half of the negative responses were "yes/no" 
items and half were "pure no" items. In the four-item/category condition, each category was paired with two instances of that category ("yes" items) and two noninstances (a "no" item and a "yes/no" item). In the two-item/category condition, each category was paired with one instance ("yes" item) and one noninstance (either a "no" or "yes/no" item). Categories and words again were selected from Battig and Montague (1969). In each condition, half of the "yes," "yes/no," and "no" items were selected to be highfrequency associates of their category (high associates, mean frequency $=395.21, S D=41.89$ ) and half were low-frequency associates of their category (low associates, mean frequency $=11.65$, $S D=1.98$ ). The "no" items were associates of either three categories (four-item/category condition) or six categories (twoitem/category condition) not used as study questions in the list. A set of three question-word pairings preceded and followed the critical list as primacy and recency buffers.

Design. The design of Experiment 2 was the same as that of Experiment 1, except for the following changes. The strength of the preexisting association of items to their categories was added as a within-subjects variable with two levels (high and low association strength). The number of categories and words per category was added as a between-subjects variable with two levels (fouritem/category and two-item/category), as was the length of delay between study and testing (immediate and delayed testing). In the delayed-testing condition, the memory tests were administered after 15 to 20 min of interpolated activity. Twenty-four subjects served in the immediate- and delayed-testing conditions. Within each testing condition, 12 subjects served in the four-item/category and twoitem/category conditions. The dependent variable was free recall.

Items were presented randomly with the constraint that a "yes/no" item not appear before at least one occurrence of the category to which it was related. Experiments 2 and 3 (to be described later) were run concomitantly, using the same subjects, so that one experiment served as part of the filler task in the delay condition of the other. The order of experiments was counterbalanced across subjects.

Procedure. The procedure employed was similar to that of Experiment 1 . Although Experiments 2 and 3 were nominally separate studies, they were conducted simultaneously using the same subjects. From their perspective, the subjects participated in a single experiment in which they studied and recalled for two independent lists of items. The subjects were instructed that each list was separate and had nothing to do with the other. The subjects first would study one list, then would complete a short filler task for $10 \mathrm{~min}$. Following this, the subjects studied the list from the other experiment and immediately completed a free-recall test for that list. The subjects then completed the free-recall test for the very first list studied. For each list, the subjects answered either "yes" or "no" to the category question that appeared with the word (striking either the $\mathrm{Y}$ or $\mathrm{N}$ key on the computer keyboard). Each item appeared on a blank screen and remained for $2 \mathrm{sec}$.

\section{Results and Discussion}

The results are shown in Table 3. The first important finding is that, contrary to expectation, strength of association did not have a significant effect on recall $[F(1,11)=$ $2.78, p>.10]$, nor did this factor interact with any other Thus, strength of association was not considered in subsequent analyses.

Type of item had a large effect on free recall $[F(2,22)=$ $55.62, p<.0001]$. As expected, in the immediate-testing condition, "yes" items were recalled more than were "no" items in both the four-item/category condition $[t(11)$ $=8.37, p<.0001]$ and the two-item/category condition $[t(11)=9.11, p<.0001]$. More importantly, "yes/no" items were recalled significantly more than were "no" items in the four-item/category condition $[t(11)=4.45, p<.001]$, replicating the yes/no effect when categorized "no" items were employed. The difference between recall of "yes/no" and "no" items was not significant in the two-item/category condition $[t(11)=$ $1.84, p>.05$ ], but it was in the expected direction.

The number of items per category did not have a significant main effect on recall $[F(1,11)=2.36, p>.10]$, nor did this factor interact with the type of item $[F(2,22)=$ $2.78, p>.05]$. Although the difference between immediate recall of "yes/no" and "no" items in the two-item/ category condition was not statistically significant, there seemed to have been an overall trend for "yes/no" items to be recalled more than "no" items in the immediaterecall condition. The yes/no effect, however, was weaker in the two-item/category than in the four-item/category condition.

The length of the retention interval had a significant effect on recall $[F(1,11)=107.53, p<.0001]$. Recall was considerably lower in the delayed-testing condition than in the immediate-testing condition. This factor did not interact significantly with number of items per category $[F(1,11)=1.15, p>.30]$, but did with the type of item $[F(2,22)=30.99, p<.0001]$. The delay of the freerecall test drove recall of "yes/no" and "no" items to basement levels, making it difficult to interpret these results. The interaction of test delay and item type implies that the advantage of "yes/no" items over "no" items is reduced or eliminated after $15 \mathrm{~min}$ of interpo-

Table 3

Proportion Free Recalled in the Immediate- and Delayed-Testing Conditions as a Function of Number of Items/Category, Item Type, and Strength of Association (Experiment 2)

\begin{tabular}{|c|c|c|c|c|c|c|c|c|c|}
\hline \multirow[b]{3}{*}{ Condition } & \multicolumn{9}{|c|}{ Item Type } \\
\hline & \multicolumn{3}{|c|}{ Yes } & \multicolumn{3}{|c|}{ Yes/No } & \multicolumn{3}{|c|}{ No } \\
\hline & $\begin{array}{c}\text { High } \\
\text { Association }\end{array}$ & $\begin{array}{c}\text { Low } \\
\text { Association }\end{array}$ & $M$ & $\begin{array}{c}\text { High } \\
\text { Association }\end{array}$ & $\begin{array}{c}\text { Low } \\
\text { Association }\end{array}$ & $M$ & $\begin{array}{c}\text { High } \\
\text { Association }\end{array}$ & $\begin{array}{c}\text { Low } \\
\text { Association }\end{array}$ & $M$ \\
\hline \multicolumn{10}{|c|}{ Four-Item/Category Condition } \\
\hline Immediate Testing & 0.36 & 0.31 & 0.33 & 0.25 & 0.25 & 0.25 & 0.08 & 0.07 & 0.08 \\
\hline Delayed Testing & 0.10 & 0.10 & 0.10 & 0.07 & 0.01 & 0.04 & 0.03 & 0.00 & 0.01 \\
\hline \multicolumn{10}{|c|}{ Two-Item/Category Condition } \\
\hline Immediate Testing & 0.28 & 0.28 & 0.28 & 0.17 & 0.15 & 0.16 & 0.11 & 0.06 & 0.08 \\
\hline Delayed Testing & 0.06 & 0.03 & 0.05 & 0.01 & 0.00 & 0.01 & 0.03 & 0.03 & 0.03 \\
\hline
\end{tabular}


lated activity. This conclusion, however, must be tentative, because the recall levels in the delayed condition were extremely low. ${ }^{4}$ The three-way interaction of factors was not significant.

Conclusions. An important finding of Experiment 2 was a significant yes/no effect in immediate recall in the four-item/category condition. This finding implies that the yes/no effect cannot be explained as the result of selective categorization of "yes/no" items, because the "no" items formed similar related groups within the study list. The effect depends critically on the relevant categories being presented during study. The yes/no effect, however, was not statistically significant in the two-item/category condition. Reducing the number of times each category appeared as a question in the study list reduced the impact of those categories on the recall of "yes/no" items, although this manipulation had little impact on the recall of "yes" and "no" items. A delay between study and testing also seemed to eliminate the yes/no effect, but this cannot be asserted with great confidence.

Like the number of presentations of categories, the strength of association between items and their categories was expected to influence the probability that categories would be elicited as IARs by "yes/no" items. A weak associate would presumably be less likely to elicit its category than would a strong associate, implying that the yes/no effect should be weaker for low-associate items than for high-associate items. In fact, the difference between recall of strong and weak associates was extremely small. The absence of this expected effect is, perhaps, understandable in terms of the frequent finding in verbal learning experiments that interitem associations improve paired-associate learning only at the very weak end of the memory scale (see Kausler, 1974, pp. 99, 155). Pair learning is better for items having some degree of association, but, beyond a minimal level, increases in normative strength of association produce little further benefit for episodic learning. One reason why strength of association had so little effect in Experiment 2 might have been that the manipulation of number of categories was far stronger than that of strength of association.

\section{EXPERIMENT 3}

Experiments 1 and 2 replicated the frequent finding that, when making category judgments, subjects better remember words that belong to the category they are paired with than words that do not (e.g., Craik \& Tulving, 1975). The major finding of Experiments 1 and 2, however, was that one obtains a similar, though weaker, effect when the related category is not actually paired with the studied word-rather, it occurs earlier in the study trial-and when subjects are not required to explicitly judge whether the word belongs to the related category. Johnson-Laird, Gibbs, and deMowbray (1978) and Ross (1981) have demonstrated that recall of words increases with the number of category decisions made about it. For example, recall is greater when a word is judged to share three fea- tures with a conjunctive category than when a word is judged to share just one feature with a conjunctive category. Experiment 3 investigated whether an analogous effect might be found in the current paradigm-that is, whether memory might also be a function of the number of implicit category judgments a subject could potentially make about an item on the basis of the entire set of category questions employed in the study list.

In Experiment 3, a special set of items was included in the study list. These items, termed "yes/yes" items, were instances of both the category they were paired with and another category in the list. The specific purpose of Experiment 3 was to determine whether recall of these "yes/yes" items would be better than that of simple "yes" items. The results of Johnson-Laird et al. (1978) give reason to predict that recall of "yes/yes" items would, in fact, be greater than that of "yes" items because they are related to two, as opposed to just one, category in the list. Ross (1981), however, found that recognition performance improves only with the number of explicit decisions made about a word during study, not with the number of categories the word may actually belong to. Consequently, it is unclear whether the presence of an additional related category elsewhere in the study list will necessarily improve recall of a word that is already paired with a related category.

\section{Method}

Subjects. Forty-eight Stanford undergraduates participated in Experiment 3 in exchange for either credit in an introductory psychology class or pay. The subjects were run in groups of 1 to 3 , and they served in both Experiments 2 and 3.

Materials. A single list was employed in Experiment 3. The structure of the list was similar to that of the four-item/category list employed in Experiment 2. Twelve categories served as the basis for study questions; each category was paired with four words, two of which were instances of the category and two of which were not. To form a list in which eight words (the "yes/yes" items) were related to two questions in the list, it was necessary to construct categories and instances specifically for Experiment 3, and it is not known how strongly related these items are to their study questions. Eight of the positive-response items were "yes/yes" items, and the rest were "yes" items. Half of the negative-response items were "yes/no" items and half were "no" items. Primacy and recency buffers of three question-word pairings preceded and followed the critical portion of the study list.

Design. The design of Experiment 3 was like that of the previous experiments, except the study list contained eight "yes/yes" items that were related to both the category they were paired with and another category question in the study list. Twenty-four subjects served in the immediate- and delayed-testing conditions. Items were presented randomly with the constraint that no "yes/no" or "yes/yes" item appear before at least one occurrence of the category to which it was related.

Procedure. The procedure was the same as that used in Experiment 2

\section{Results and Discussion}

The results are shown in Table 4 . Both type of item $[F(3,69)=54.55, p<.0001]$ and retention interval $[F(1,23)=87.57, p<.0001]$ had large effects on free recall. Given immediate recall, "yes" items were recalled 
Table 4

Proportion Free Recalled in Experiment 3

\begin{tabular}{lcccc} 
& \multicolumn{4}{c}{ Item Type } \\
\cline { 2 - 5 } \multicolumn{1}{c}{ Condition } & Yes/Yes & Yes & Yes/No & No \\
\hline Immediate Testing & 0.48 & 0.41 & 0.21 & 0.12 \\
Delayed Testing & 0.15 & 0.14 & 0.07 & 0.02 \\
\hline
\end{tabular}

more than were "yes/no" items $[t(23)=5.63$, $p<.001]$, which were recalled more than were "no", items $[t(23)=2.35, p<.05]$. The major finding, though, is that recall of "yes/yes" items was significantly greater than that of "yes" items $[t(23)=2.93, p<.01]$. However, type of item and test delay interacted $[F(3,69)=13.41, p<.0001]$, and in the delayed-test condition, recall of "yes/yes" and "yes" items did not differ significantly $[t(23)=0.63, p>.50]$.

Conclusions. The main finding of Experiment 3 is that "yes/yes" items are better remembered than "yes" items in an immediate test of recall. Multiple explicit category judgments improve memory (Johnson-Laird et al., 1979; Ross, 1981). Experiment 3, however, demonstrated that it is not necessary that all category judgments be made explicitly in order to improve memory performance. It is not even necessary to present all the relevant categories with the target item. Items seem to elicit IARs referring to earlier categories even when they belong to the category they are paired with. These implicit responses then act like additional category judgments, enhancing memory.

\section{EXPERIMENT 4}

A major question that remains unanswered by the previous experiments is whether the subjects were being explicitly reminded of previous orienting questions while studying items in a list. Subjects are apparently more likely to generate a particular category as an IAR if they have recently encountered it. It seems likely, though, given the nature of the stimulus materials used, that the subjects discerned the nature of the experimental manipulation and became aware of many of the categorical relations between items in the lists. The subjects often mentioned informally that they had realized that many words in the study lists were related to a category other than the one they were paired with. None of the previous experiments, however, directly addressed the issue of whether subjects actually need to be aware of the relation of a "yes/no" item to a category in order for that relation to enhance memory. Experiment 4 examined whether recall of "yes/no" and "yes/yes" items is enhanced if the subject is unaware that a related category question has preceded the item.

In Experiment 4, the subjects answered two questions about each word: whether the item belonged to the category that it was paired with at the time of study, and whether it belonged to any other category question they had seen in the list. On this basis, it is possible to consider separately recall of "yes/no" items that the subject recognized were related to a category in the list and those that the subject did not recognize were related to a category. The question of interest is whether recall of "yes/no" items will exceed that of "no" items in the latter case.

\section{Method}

Subjects. Twenty-four Stanford undergraduates participated in Experiment 4 in exchange for credit in an introductory psychology class. The data of one subject were lost due to experimenter error.

Materials. A single list of 96 critical question-word pairs was employed in Experiment 4. The list was composed of 24 categories, each paired with four words, two positive and two negative responses. The categories and words were taken from Experiments 2 and 3. Eight of the positive-response items were "yes/yes" items, and the remainder were "yes" items. Half of the negativeresponse items were "yes/no" items, and half were "no" items. The strength of association of "yes/yes" items to their categories was not known because these materials were constructed by the experimenter. Half of the "yes," "yes/no," and "no" items were high associates (mean frequency $=340.75, S D=93.31$ ) and haif were low associates (mean frequency $=12.84, S D=4.16$ ) of their category. A buffer of five question-word pairings preceded and followed the critical items.

Design. The design was similar to that of the previous experiments. The most important change was that the subjects answered two study questions as each target word was presented. First, the subject was requested to give a category judgment pertaining to the category the current word was paired with. Second, he/she was asked whether the current word belonged to any other category the subject had seen up to that point. Each question required only a "yes" or "no" answer. The study list was doubled in size primarily to offset the expected improvement in recall due to the longer and more elaborate study task. Strength of association was not considered as a factor, because the association strengths of "yes/yes" items were not known, and this factor did not affect recall in Experiment 2 .

Procedure. The subjects studied only one list. During each trial of list learning, a word and the category paired with that word would appear together on the computer screen. The subjects first indicated whether the word was an instance of that category or not by striking either the Y key (for "yes") or the N key (for "no") on the computer keyboard. The category remained on the screen for $2.5 \mathrm{sec}$ before disappearing. The target word did not disappear at this point, but remained on the screen by itself. The subjects then indicated whether the target word belonged to any other category previously encountered, again by striking either the $\mathrm{Y}$ or $\mathrm{N}$ key. The word remained on the screen for an additional $2.5 \mathrm{sec}$ before being replaced by the next item in the sequence, for a total presentation time of $5 \mathrm{sec}$ per target item. The subjects made these two judgments for each item in the list. Following the study phase, the subjects completed a free-recall test.

\section{Results and Discussion}

During the study phase, the subjects sometimes made an inappropriate response (striking a key other than the $\mathrm{Y}$ or N key) to one or both study questions of an item. These items were excluded from all analyses.

The main purpose of Experiment 4 was to investigate recall performance as a function of the subjects' responses to the second study question (response type)-that is, whether the subjects recognized or believed that a target item was, or was not, related to some category appearing earlier in the study list. Table 5 displays, in addition to overall recall levels (all items), the average recall for items to which the subjects responded positively to the 
Table 5

Proportion Recalled on the Basis of Subjects' Responses to the Second Orienting Question in Experiment 4

\begin{tabular}{|c|c|c|c|c|}
\hline \multirow[b]{2}{*}{ Response } & \multicolumn{4}{|c|}{ Item Type } \\
\hline & Yes/Yes & Yes & Yes/No & No \\
\hline All Items & 0.55 & 0.36 & 0.37 & 0.20 \\
\hline Positive & 0.57 & 0.43 & 0.43 & 0.31 \\
\hline Negative & 0.47 & 0.34 & 0.16 & 0.18 \\
\hline
\end{tabular}

second question (positive items) and those to which they responded negatively (negative items). Positive items are those that the subject believed were related to a category other than, or in addition to, the one paired with it; negative items are those that the subject believed were not related to a category other than, or in addition to, the one paired with it.

The data from all items replicate the findings of Experiment 3 , except there was no significant difference between recall of "yes/no" and "yes" items $[t(22)=0.39$, $p>.50]$. Type of item, however, had a significant effect on recall $[F(3,66)=20.90, p<.0001]$, and "yes/no" items were recalled significantly more than were "no" items $[t(22)=5.69, p<.0001]$.

The major findings are that response type had a significant effect on recall $[F(1,22)=21.96, p<.001]$, and this factor interacted with type of item $[F(3,66)=$ $3.75, p<.02$ ]. Recall of positive items exceeded that of negative items. Thus, the subjects were much more likely to recall a word if they had responded positively to the second orienting question than if they had responded negatively. The significant interaction effect, though, indicates that type of item did not have the same effect on positive and negative items. Specifically, in the positiveresponse condition, "yes/no" items were recalled significantly more than were "no" items $(z=3.33, p<.001)$, but in the negative-response condition, "yes/no" items were no better recalled than were "no" items $(z=0.71$, $p>.05$ ). The yes/no effect occurred only for items that the subject explicitly recognized as a member of a category in the study list. Interestingly, "yes/yes" items were recalled significantly more than were "yes" items even in the negative-response condition.

Conclusions. Experiment 4 yielded two main findings. First, when the subjects believed that a word was related to a category that had appeared in the study list, they tended to remember that word better than they remembered a word they believed was not related to any category. Second, a yes/no effect was found only for positive items that the subject had recognized were related to a category in the list. There was no yes/no effect for negative items that the subject believed were not related to a category. The first finding is consistent with the results of Experiment 3 and the studies by Johnson-Laird et al. (1979) and Ross (1981). When the subjects decided a word was related to a category other than, or in addition to, the one it was paired with, they were essentially making a second category decision in favor of that word, which enhanced memory for it. The second finding offers a clear answer to the question that motivated this experiment: Subjects exhibit a yes/no effect only when they are aware of the relevant relations between earlier category questions and words in the study list. The results offer no evidence that truly implicit, nonconscious, processing of "yes/no" items had occurred in Experiment 4, although "yes/yes" items did seem to benefit from category associations the subject was not explicitly aware of. The results further imply that the yes/no effect depends on subjects' consciously encoding a relevant category relation at the time of study.

\section{GENERAL DISCUSSION}

The results of four experiments have demonstrated that recall of a target word in a list-learning experiment can be greatly influenced by the processing carried out on previously encoded words. The results of Experiment 1 demonstrate the basic phenomenon that recall of words not related to their own study question is enhanced by the presence of a related category question elsewhere in the study list. Moreover, it was later found in Experiment 3 that even words that are related to their study question benefit from the presence of other related questions in the list. The results of Experiment 2 reveal that this yes/no effect is sensitive to the frequency of categories in the study list and the length of the delay between study and testing. The phenomenon, however, is apparently not greatly affected by the preexisting associative strength between words and categories. Finally, the results of Experiment 4 demonstrate that the phenomenon is contingent upon conscious awareness. When the subjects were not aware of the relation between "yes/no" items and their related category, they recalled those "yes/no" items no better than they did "pure no" items.

The results of the present experiments can be explained fairly well by the human associative memory (HAM) theory (Anderson \& Bower, 1973; Bower, 1972). This theory assumes that episodic memory is closely related to one's permanent memory of facts and ideas, or semantic memory (see Tulving, 1972). According to HAM, incoming information is checked for its relation to permanent associative structures in memory, and any relation discovered is utilized in establishing the episodic trace of the event. For example, if two words, LION and DOG, are studied together, the semantic association between the two as animals would be activated, and this association would be encoded in the episodic representation of the two words. Thus, new information is presumed to be encoded according to a framework of associations provided by permanent memory, although the model also assumes that weak episodic associations can be formed by the mere contiguity of elements at the time of study. Recall in HAM is cue dependent, and free recall requires provision of a list cue-some specification of the set of information the individual is to reproduce or a general context associated 
with the presentation of the list (see Anderson \& Bower, 1972). Recall begins with the activation of the list cue, which spreads activation along associations to elements of the list. Retrieval occurs by the activation of a memory item by input from the retrieval cue or from a related item that has itself been activated.

The results of the taxonomic conditions in the present experiments can be explained by HAM if it is assumed that the episodic representation of the studied list is comprised of both to-be-remembered words and the categories specified in the study questions. A fragment of such an episodic network is depicted in Figure 1. To-be-remembered items that were "no" responses will be episodically associated to the category they appeared with during study. To-be-remembered items that were "yes" responses to their category question, however, have, in permanent memory, a preexisting association to the category that is incorporated in the memory trace. Consequently, the association between a "yes" item and its category will be far stronger than the episodic association of a "no"' item to the arbitrary category used to query it. Stronger associations are more likely to be initially encoded and more likely to lead to the activation of an item during retrieval, accounting for the superior recall of "yes" items.

The main manipulation employed in the current study was to place categories in the list that were related to

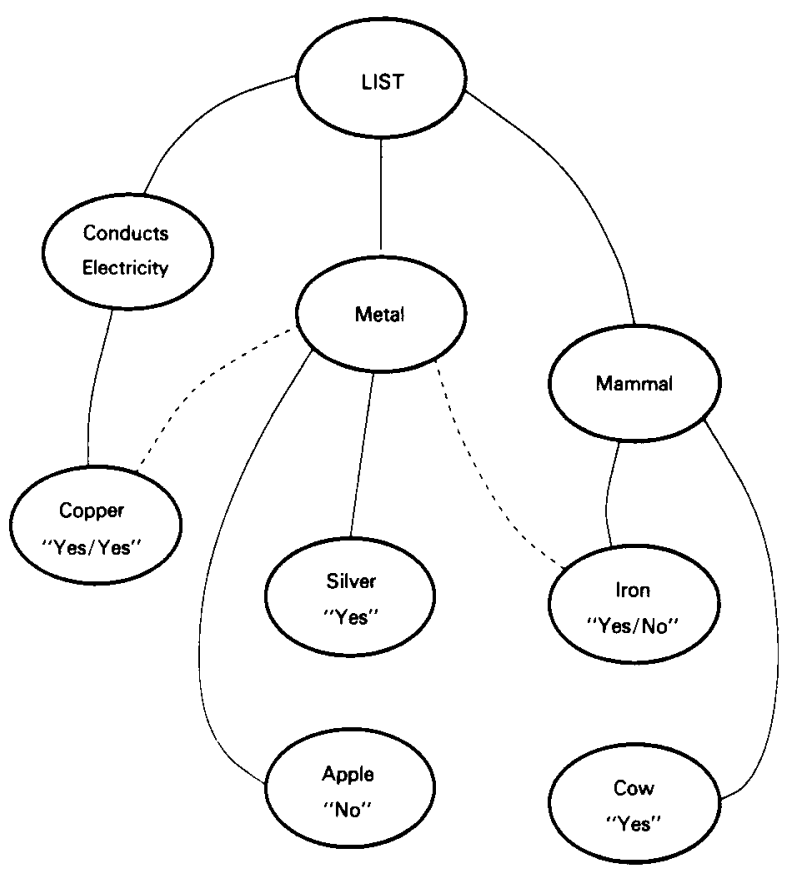

Figure 1. A schematic diagram of the sort of episodic network proposed by HAM. The list cue is shown associated to categories appearing on the second level, which are associated to individual words. Associations from the list cue to words are omitted for the sake of clarity. Explicit associations are shown as complete lines; implicit associations are shown as dashed lines. negative-response items. These "yes/no" items should have a weak episodic association to the category they appeared with during study, but the preexisting semantic association between the item and its related category also has the potential to be activated during encoding and to be represented in the episodic trace. In this case, the implicit association between the two, as shown in Figure 1, would be encoded. Such a "yes/no" item would be better recalled than would a "pure no" item because the former has a strong semantic association to a category in the list, whereas a "no" item has only a weak episodic link to a category. A "yes/no" item would be recalled less than would a "yes" item because there is some probability that the association between the "yes/no" item and its related category would not be encoded. The subject never sees a "yes/no" item and its related category together, and so must rely on the implicit processing of the association between the item and category for the association to be encoded. In the case of "yes" items, the association between the word and category is explicitly given to the subject at the time of encoding, and that association is activated as part of the question-answering procedure.

HAM also predicts that the benefit to recall of a "yes/no" item will depend on the likelihood that the item will remind the subject of an earlier, related category. Only if the subject is reminded of a category will the "yes/no" item be encoded and strengthened in association to that category. The results of Experiments 2 and 4 are consistent with this analysis. The advantage of the "yes/no" items over the pure "no" items was much weaker when the number of instances of each category were reduced from four to two. Given fewer presentations, a category will be less primed as an IAR and less likely to be thought of during encoding, reducing the probability of strengthening the association between "yes/no" items and the category. Moreover, when the subject is not consciously aware of the association at the time of study, the association is not encoded and does not influence recall (see Experiment 4).

How do several other popular models of memory fare in explaining the data reported here, specifically the enhanced recall of the "yes/no" items? The answer, in each case, depends on whether or not the theory includes some means of activating implicit associations to "yes/no" items. Hintzman's $(1984,1986)$ multiple trace model, MINERVA, for example, is basically a passive recorder of events that stores presented items independently of one another. The goodness of encoding of any particular item in a list is a function of a learning rate determined by either the overall situation or the particular encoding task applied to the item (Hintzman, 1986). Thus, this model has no direct means for encoding the relation of a "yes/no" item to an earlier category, nor of enhancing the item's later recall. Eich's (1982) distributed memory model, CHARM, has similar difficulties because this model does not stipulate how preexisting associations would enhance the en- 
coding and recall of "yes/no" items but not enhance "pure no" items in the reported experiments. According to CHARM, explicitly pairing similar items, such as a category and an instance of that category, results in a stronger representation of both, because the category and instance are "convolved" at encoding (Eich, 1985). On the other hand, the presence of similar items throughout a list, such as a "yes/no" item and an earlier category, can actually impair recall of any given item, because items become "blended" and less distinguishable in a cumulative memory trace (Eich, 1982).

Raaijmakers and Shiffrin's (1980, 1981) SAM model offers a better prospect of accounting for the yes/no effect because SAM assumes that item-to-item associations play a major role in searching memory during free recall. In this account, a "yes/no" item would be recalled somewhat better than would a "no" item because the former has preexisting associations to the "yes" items paired with the related category. Should the "yes" items, or the category itself, be recalled, associated "yes/no" items would be cued for recall. Two observations weaken this hypothesis. First, when "no" items were interrelated members of a common category (see Experiment 2), they should have cued one another's recall roughly as much as "yes" and "yes/no" items did. Yet, recall of "no" items was considerably worse than that of "yes/no" items. Second, Experiment 4 demonstrated that the yes/no effect is largely due to encoding; "yes/no" items recognized as members of an earlier category were recalled better than were "no" items, whereas those not so recognized, and so encoded, were recalled as poorly as "no" items. The latter result suggests that interitem cuing at the time of retrieval is not a very powerful determinant of the yes/no effect.

All these theories can, of course, be augmented to include IARs to the "yes/no" items, and thereby encode the enriched memory traces needed to produce enhanced recall of "yes/no" items. In SAM, for instance, it might be assumed that an item, during study, may first retrieve a category associate so that the memory trace of the item includes not only information about the explicit study question but also about the implicit category the subject thought of when the item was presented. This implicit category would then be a potent retrieval cue for the item. MINERVA and CHARM could be similarly augmented to account for the yes/no effect. The experiments reported here, though, argue that each theory would need to assume three things in order to explain the results reported in this study: (1) a preexisting network of associations in which particular category-to-item connections can be primed, (2) an ability to have implicit associations arise during study of an item, and (3) use of these implicit associations to improve recall. It is awkward to implement such additions in several of the theories, especially the second assumption that IARs become part of the encoding experience recorded into memory. The results of Experiment 4 , though, remind us that subjects think about to-be-remembered items during learning trials, that their thoughts stray away from the orienting question asked about an item, and that their thoughts about an item will often influence how that item is stored and later retrieved.

\section{REFERENCES}

ANDERSON, J. R., \& Bower, G. H. (1972). Recognition and retrieval processes in free recall. Psychological Review, 79, 97-123.

ANDERSON, J. R., \& BOWER, G. H. (1973). Human associative memory. New York: Wiley.

Battig, W. F., \& Montague, W. E. (1969). Category norms for verbal items in 56 categories: A replication and extension of the Connecticut category norms. Journal of Experimental Psychology Monograph, 80, 1.46 .

BousfieLD, W. A. (1953). The occurrence of clustering in the recall of randomly arranged associates. Journal of General Psychology, 49, 229-240.

BousfIELD, W. A., \& COHEN, B. H. (1958). The occurrence of clustering in recall of randomly arranged words of different îrequencies of usage. Journal of General Psychology, 52, 83-95.

BowER, G. H. (1972). A selective review of organizational factors in memory (pp. 93-137). In E. Tulving \& W. Donaldson (Eds.), Organization of memory. New York: Academic Press.

BowER, G. H. (1975). Cognitive psychology: An introduction. In W. K. Estes (Ed.), Handbook of learning and cognition (pp. 25-80). Hillsdale, NJ: Erlbaum.

COFER, C. N. (1965). On some factors in the organizational characteristics of free recall. American Psychologist, 20, 261-272.

Craik, F. I. M., \& LoCKharT, R. S. (1972). Levels of processing: A framework for memory research. Journal of Verbal Leaming \& Verbal Behavior, 11, 671-684.

Craik, F. I. M., \& Tulving, E. (1975). Depth of processing and the retention of words in episodic memory. Journal of Experimental Psychology: General, 104, 268-294.

EICH, J. M. (1982). A composite holographic associative recall model. Psychological Review, 89, 627-661.

EICH, J. M. (1985). Levels of processing, encoding specificity, elaboration, and CHARM. Psychological Review, 92, 1-38.

Ekstrand, B. R., Wallace, W. P., \& Underwood, B. J. (1966). A frequency theory of verbal discrimination learning. Psychological Review, 73, 566-578.

Hintzman, D. L. (1984). MineRVA 2: A simulation model of human memory. Behavior Research Methods, Instruments, \& Computers, 16, 96-101.

HinTZMAN, D. L. (1986). "Schema abstraction"' in a multiple-trace memory model. Psychological Review, 95, 411-428.

HyDE, T. S., \& JENkINS, J. J. (1969). Differential effects of incidental tasks on the organization of recall of a list of highly associated words. Journal of Experimental Psychology, 82, 472-480.

JACOBY, L. L. (1974). The role of mental contiguity in memory: Registration and retrieval effects. Journal of Verbal Leaming \& Verbal Behavior, 13, 483-496.

JACOBY, L. L., \& CRAIK, F. I. M. (1979). Effects of elaboration of processing at encoding and retrieval: Trace distinctiveness and recovery of initial context. In F. I. M. Craik \& L. S. Cermak (Eds.), Levels of processing in human memory (pp. 1-21). Hillsdale, NJ: Erlbaum.

JohnSon-Laird, P. N., GibBs, G., \& DEMowbray, J. (1978). Meaning, amount of processing, and memory for words. Memory \& $\mathrm{Cog}$ nition, 6, 372-375.

KAUSLER, D. N. (1974). The psychology of verbal learning and memory. New York: Academic Press.

Lockhart, R. S., Craik, F. I. M., \& JaCoby, L. (1976). Depth of processing, recognition and recall. In J. Brown (Ed.), Recall and recognition (pp. 75-102). London: Wiley.

LUPKER, S. J., \& Williams, B. A. (1989). Rhyme priming of pictures and words: A lexical activation account. Journal of Experimental Psychology: Learning, Memory, \& Cognition, 15, $1033-1046$. 
Marshall, G. R. (1967). Stimulus characteristics contributing to organization in free recall. Journal of Verbal Learning \& Verbal Behavior, 6, 364-374.

Moscovitch, M., \& Craik, F. I. M. (1976). Depth of processing, retrieval cues, and uniqueness of encoding as factors in recall. Journal of Verbal Learning \& Verbal Behavior, 15, 447-458.

NeLSON, D. L. (1989). Implicitly activated knowledge and memory. In C. lzawa (Ed.), Current issues in cognitive processes: The Tulane Floweree Symposium on cognition (pp. 369-387). Hillsdale, NJ: Erlbaum.

Nelson, D. L., Bajo, M. T., \& Canas, J. (1987). Prior knowledge and memory: The episodic encoding of implicitly activated associates and rhymes. Joumal of Experimental Psychology: Learning, Memory, \& Cognition, 13, 54-63.

Nelson, D. L., \& McEvoy, C. L. (1979). Encoding context and set size. Joumal of Experimental Psychology: Human Leaming \& Memory, $5,292-314$.

Penguin rhyming dictionary (1985). New York: Penguin.

RaAimakers, J. G. W., \& Shiffrin, R. M. (1980). SAM: A theory of probabilistic search of associative memory. In G. H. Bower (Ed.), The psychology of learning and motivation (pp. 207-262). New York: Academic Press.

RaAimMakers, J. G. W., \& Shiffrin, R. M. (1981). Search of associative memory. Psychological Review, 88, 93-134.

Ross, B. H. (1981). The more, the better?: Number of decisions as a determinant of memorability. Memory \& Cognition, 9, 23-33.

Tulving, E. (1972). Episodic and semantic memory. In E. Tulving $\&$ W. Donaldson (Eds.), Organization of memory (pp. 381-403). New York: Academic Press.
UNDERWOOD, B. J. (1965). False recognition produced by implicit verbal responses. Journal of Experimental Psychology, 70, 122-129.

UNDERWOOD, B. J., \& SCHULz, R. W. (1960). Meaningfulness and verbal learning. Philadelphia: Lippincott.

WOOD, G., \& UNDERWOOD, B. J. (1967). Implicit responses and conceptual similarity. Journal of Verbal Learning \& Verbal Behavior, 6, $1-10$

\section{NOTES}

1. A post hoc analysis of the rhyming materials was made in terms of The University of South Florida rhyme category norms provided by Cathy L. McEvoy and Douglas L. Nelson. The mean frequency of generation of the rhyme materials to their sound class was 16.33 ( $n=$ 260 ), but with a large standard deviation of 18.23 .

2. While only free-recall data are reported, the subjects in all experiments completed cued-recall tests following the free-recall tests. In general, the results of cued recall mirror those of free recall, replicating all major effects. A notable exception is that provision of extralist cues for "no" items produced recall equal to that of "yes/no" items. These data are available on request.

3. Individual means in this and subsequent experiments were compared by standard paired- $t$ tests.

4. Some support for this conclusion comes from unreported cued-recall data in which a yes/no effect in immediate testing was eliminated by delayed testing.

(Manuscript received September 1, 1989; revision accepted for publication December 13, 1989.) 